\title{
Osteonecrosis of the humeral head
} in a human immunodeficiency virus-infected patient under tenofovir disoproxil fumarateemtricitabine-lopinavir/ritonavir for 10 years: a case report

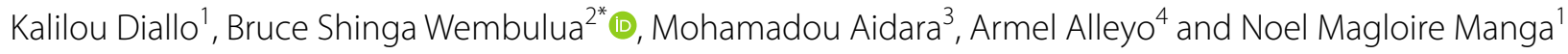

\begin{abstract}
Background: Human immunodeficiency virus-infected patients are 100 times more likely to develop aseptic osteonecrosis compared with the general population. While $90 \%$ of cases concern the femoral head, the involvement of humeral bone remains rare.

Case presentation: We report a case of aseptic osteonecrosis of the left humeral head complicating antiretroviral therapy in a female, 46-year-old, Bissau-Guinean human immunodeficiency virus-infected patient received in a context of progressive pain in the left shoulder followed by limitation of articular movements. Standard $x$-ray of the shoulder allowed us to make the diagnosis by showing a typical image of osteonecrosis. The treatment was medical combined with physiotherapy.

Conclusions: Aseptic osteonecrosis should be systematically looked for in human immunodeficiency virus patients on antiretroviral treatment. In addition to femoral head aseptic necrosis, the involvement of the humeral bone should also be considered.
\end{abstract}

Keywords: Aseptic osteonecrosis, Humeral head, HIV-infected patients, Antiretroviral therapy, Case report

\section{Background}

Antiretroviral therapy has drastically reduced the morbidity and mortality associated with human immunodeficiency virus (HIV) infection [1]. However, new concerns have arisen from its side effects, some of which affect the bones. HIV-infected patients are 100 times more likely to develop aseptic osteonecrosis (AON) compared with the general population [2]. This concerns in $90 \%$ of cases the femoral head $[2,3]$. The involvement of the humeral

\footnotetext{
*Correspondence: bruliawems@gmail.com

${ }^{2}$ Department of Infectious and Tropical Diseases, Fann University Hospital, Dakar, Senegal
}

Full list of author information is available at the end of the article bone remains rare [4]. We report a case of $\mathrm{AON}$ of the left humeral head complicating antiretroviral therapy in a patient infected with HIV-2 at the 10th year of treatment.

\section{Case presentation}

A 46-year-old, Bissau-Guinean patient who had been HIV-2-positive since 2006 was hospitalized in the medical service of the Hospital de la Paix in Ziguinchor, Senegal for pain in the left shoulder of progressive installation, accompanied by limitation of articular movements. These symptoms had been evolving for 2 years before her admission. In her history, there was no indication of trauma, long-term corticosteroid therapy, or diabetes 
or sickle cell disease. She was under antiretroviral treatment consisting of tenofovir disoproxil fumarate-emtricitabine-lopinavir/ritonavir (TDF-FTC-LPv/r) with good treatment compliance. On general examination, she had clear consciousness, temperature $36.5^{\circ} \mathrm{C}$, respiratory rate (RR) 20 cycles per minute, blood pressure $120 / 80 \mathrm{mmHg}$, height $1.72 \mathrm{~m}$, weight $55 \mathrm{~kg}$, body mass index $16.95 \mathrm{~kg} /$ $\mathrm{m}^{2}$. On physical examination, there was no deformity of the shoulder. However, mobilization was limited by pain. In addition, there was oral candidiasis. Laboratory tests revealed serum creatinine at $25 \mathrm{mg} / \mathrm{l}$ (clearance of creatinine $22.06 \mathrm{~kg} / \mathrm{m}^{2}$ ), uremia at $0.81 \mathrm{~g} / \mathrm{l}$, proteinuria at $2.03 \mathrm{~g} / 24$ hours, and serum calcium at $72.4 \mathrm{~g} / \mathrm{l}$. Immunovirologically, cluster of differentiation 4 (CD4) count was 24 cells $/ \mathrm{mm}^{3}$ and the viral load was 55,000 copies/ $\mathrm{ml}$. Kidney ultrasound was normal. Left shoulder $\mathrm{x}$-ray showed a patch of osteolysis (Fig. 1, red arrow) on the humeral head with a clear borderline of osteosclerosis (Fig. 1, black arrow). The lesion was centered by an osteocondensed image (Fig. 1, long black arrow) with an appearance of cortical rupture typical of systemic osteonecrosis. We also noted a conservation of the spherical aspect of the humeral head and an integrity of the glenoid of the scapula. This made it possible to classify osteonecrosis as stage III of Ficat and Arlet. The treatment was medical using analgesics and antiinflammatory drugs

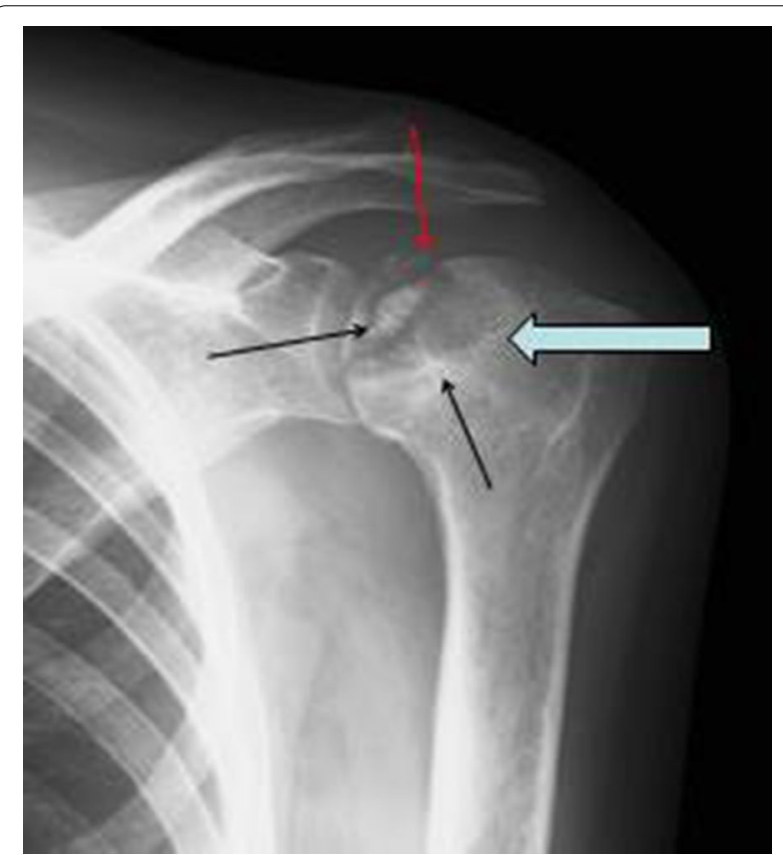

Fig. 1 The left shoulder $x$-ray showed a patch of osteolysis (thick blue arrow) on the humeral head with a clearosteosclerosis border line (small black arrow). The lesion is centered by an osteocondensed image (long black arrow) with an appearance of cortical rupture typical of systemic osteonecrosis (red arrow) combined with physiotherapy. This relieved the pain and prevented stiffness of the joint.

\section{Discussion and conclusions}

Bone complications, initially considered rare, are increasingly being reported in patients living with HIV (PLWHIV) [3]. They are 100 times more at risk of developing $\mathrm{AON}$, and this commonly concerns the femoral head $[2,3]$. Studies mostly carried out in men over the age of 40 years report the prevalence of osteoporosis in people living with HIV as being between $3 \%$ and $22 \%$ and that of osteopenia at about 23-65\% [5, 6]. Humeral localization remains rare and affects less than $10 \%$ of patients with osteonecrosis $[7,8]$. The average age of onset is between 40 and 50 years $[9,10]$. Our clinical case is one of the rare observations of humeral AON reported in PLWHIV in Senegal.

The diagnosis of osteonecrosis of the humeral head is based on clinical arguments and imaging [magnetic resonance imaging (MRI), bone densitometry, computed tomography $(\mathrm{CT})$, or $\mathrm{x}$-ray]. The pain with limitation of joint movements observed in our patient is a classic revealing sign, although a few asymptomatic cases are also reported [2]. The standard x-ray of the shoulder allowed us to make the diagnosis by showing a typical image of osteonecrosis.

The etiology of osteonecrosis during HIV infection is multifactorial. The initiation of antiretroviral therapy (ART) leads to a reduction in bone mineral density [2] comparable in magnitude to that observed during the perimenopausal period and during corticosteroid therapy [8]. This bone loss is greater on tenofovir disoproxil fumarate (TDF) regimens, less with integrase inhibitors, and rarely with protease inhibitors (PI) [11]. One year on a TDF-based regimen multiplies the risk of osteonecrosis by 4 [12].

Corticosteroid use and alcoholism are also essential risk factors for AON but not specific for $\operatorname{HIV}[2,12]$. Anticardiolipid antibodies, common in patients with HIV infection, have also been implicated as they promote damage to the vascular endothelium, platelet aggregation, and vascular thrombosis. The acquired protein $\mathrm{S}$ deficiency would be an associated factor [13]. History of acquired immunodeficiency syndrome (AIDS) and duration of infection, low CD4 count, and duration of exposure to combination antiretroviral drugs are other factors described in the literature $[2,14]$. Our patient had been on TDF/FTC/LPv/r for 10 years with a low CD4 count. She was not an alcoholic or diabetic and was not on a corticosteroid. In addition, renal failure with hypocalcemia observed in our patient may have played a role in bone weakening. 
The pathophysiology of osteonecrosis is poorly understood, but the main mechanism is vascular occlusion leading to bone hypoxia and necrosis $[13,14]$. Inflammation, as well as bleeding disorders demonstrated by high levels of D-dimer and C-reactive protein, was also linked to the risk of osteonecrosis [15].

The management of AON in HIV-infected patients has no specificity compared with the general population [16]. At the early stage, treatment is medical, combining analgesics with physiotherapy. Drilling with bone marrow transplants can also be proposed. Later, the treatment is surgical and consists of cementoplasty, removal of sequesters, or total shoulder prosthesis when there is glenohumeral arthritis [13, 17-19].

Antiretroviral treatments are responsible for severe complications that require regular monitoring. Aseptic osteonecrosis associated with TDF or protease inhibitors should be systematically looked for to prevent the progression to terminal stages. In addition to the femoral head, the involvement of the humeral bone should also be considered.

\section{Abbreviations}

AON: Aseptic osteonecrosis; IP: Protease inhibitors; ART: Antiretroviral therapy; PLWHIV: Patients living with HIV; TDF: Tenofovir disoproxil fumarate; LPV/r: Lopinavir/ritonavir; FTC: Emtricitabine.

\section{Acknowledgements}

Not applicable.

\section{Authors' contributions}

KD, BSW, MA, AA: diagnosis and management of patient, writing and editing of manuscript; NMM: overall coordination, designing, writing and editing of manuscript. All authors read and approved the final manuscript.

\section{Funding}

Not applicable.

\section{Availability of data and materials}

All relevant data and materials are included in the manuscript.

\section{Declarations}

Ethics approval and consent to participate Not applicable.

\section{Consent for publication}

Written informed consent was obtained from the patient for publication of this case report and any accompanying images. A copy of the written consent is available for review by the Editor-in-Chief of this journal.

\section{Competing interests}

The authors declare that they have no competing interests.

\section{Author details}

${ }^{1}$ Unit of Infectious and Tropical Diseases, Assane Seck University, Hospital de la Paix, Ziguinchor, Senegal. ${ }^{2}$ Department of Infectious and Tropical Diseases, Fann University Hospital, Dakar, Senegal. ${ }^{3}$ Unit of Radiology, Hospital de la Paix, Ziguinchor, Senegal. ${ }^{4}$ Unit of Orthopedics and Traumatology, Hospital de la Paix, Ziguinchor, Senegal.
Received: 19 January 2021 Accepted: 8 October 2021

Published online: 18 December 2021

\section{References}

1. Hogg RS, Yip B, Kully C, Craib KJ, O'Shaughnessy MV, Schechter MT, et al Improved survival among HIV-infected patients after initiation of tripledrug antiretroviral regimens. CMAJ. 1999;160(5):659-65.

2. Morse CG, Mican JM, Jones EC, Joe GO, Rick ME, Formentini E, et al. The incidence and natural history of osteonecrosis in HIV infected adults. Clin infect Dis. 2007:44:739-48.

3. Mary-Krause M, Billaud E, Poizot-Martin I, Simon A, Dhiver C, Dupont C, et al. Risk factors for osteonecrosis in HIV-infected patients: impact of treatment with combination antiretroviral therapy. AIDS. 2006;20:1627-35

4. Brown TT, Qaqish RB. Antiretroviral therapy and the prevalence of osteopenia and osteoporosis: a metaanalytic review. AIDS. 2006;20:2165-74.

5. Cazanave C, Dupon M, Lavignolle-Aurillac V, Barthe N, Lawson-Ayayi S, Mehsen N, et al. Reduced bone mineral density in HIV-infected patients: prevalence and associated factors. AIDS. 2008;22:395-402.

6. Amorosa V, Tebas P. Bone disease and HIV infection. Clin Infect Dis. 2006;42:108-14.

7. Fisher DE, Bickel WH. Corticosteroid-induced avascular necrosis. A clinical study of seventy-seven patients. J Bone Joint Surg Am. 1971;53:859-73.

8. Insalata JC, Pagnani MJ, Warren RF, Dines DM. Humeral head osteonecrosis: clinical course and radiographic predictors of outcome. J Shoulder Elbow Surg. 1996;5:355-61.

9. Matsen FA 3rd. The shoulder. Philadelphia: Saunders; 1998. p. 840-964.

10. Neer CS 2nd. Shoulder reconstruction. Philadelphia: Saunders; 1990. p. $143-241$.

11. Grant PM, Cotter AG. Tenofovir and Bone Health. Curr Opin HIV AIDS. 2016;11(3):326-32.

12. Morse CG, Dodd LE, Nghiem K, Costello R, Csako G, Lane HC, et al. Elevations in D-dimer and $\mathrm{C}$-reactive protein are associated with the development of osteonecrosis of the hip in HIV-infected adults. AIDS. 2013;27:591-5.

13. Hernigou. Ostéonécroses non traumatiques des épiphyses de l'adulte. EMC (Elsevier SAS, Paris), Appareil locomoteur, 14-028-A-10, 2006.

14. Grant PM, Kitch D, McComsey GA, Dube MP, Haubrich R, Huang J, et al. Low baseline CD4+ count is associated with greater bone mineral density loss after antiretroviral therapy initiation. Clin Infect Dis. 2013;57(10):1483-8.

15. Cotter AG, Sabin CA, Simelane S, Macken A, Kavanagh E, Brady JJ, et al. Relative contribution of HIV infection, demographics and body mass index to bone mineral density. AIDS. 2014;28(14):2051-60.

16. Yombi JC, Vandercam B, Wilmes D, Dubuc JE, Vincent A, Docquier PL. Osteonecrosis of the femoral head in patients with type 1 human immunodeficiency virus infection: clinical analysis and review. Clin Rheumatol. 2009;28:815-23.

17. Mont MA, Cherian JJ, Sierra RJ, Jones LC, Lieberman JR. Nontraumatic osteonecrosis of the femoral head: where do we stand today? A ten-year update. J Bone Joint Surg Am. 2015;97:1604-27.

18. Bayard C, Ledergerber B, Flepp M, Lecompte T, Moulin E, Hoffmann M, Swiss HIV Cohort Study, et al. Associations between antiretroviral treatment and avascular bone necrosis: the Swiss HIV cohort study. Open Forum Infect Dis. 2017;4(4):ofx177.

19. Yeni P. Complications associées au VIH et aux traitements antirétroviraux. Groupe des experts prise en charge médicale des personnes infectées par le VIH. Paris 2010; 131

\section{Publisher's Note}

Springer Nature remains neutral with regard to jurisdictional claims in published maps and institutional affiliations. 